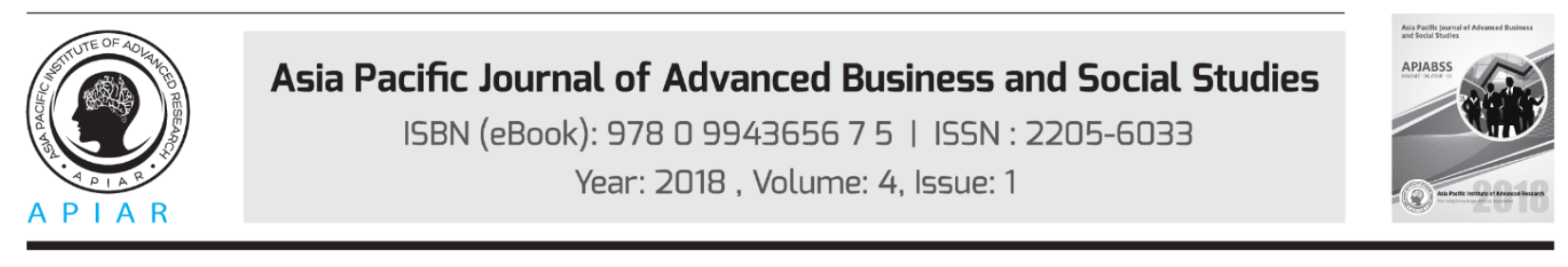

\title{
AN ANALYSIS OF AIRLINE/AIRPORT LOUNGE SERVICE USING DATA GATHERED FROM AIRLINEQUALITY.COM
}

\author{
Bình Nghiêm-Phú \\ Fukushima National College of Technology, Fukushima, Japan \\ Email: binhnghiem@gmail.com
}

\begin{abstract}
This study aims to verify the correlation between customers' evaluation of airport/airline lounge service categories and their intention to recommend the lounge, as well as that between atmospheric/affective and cognitive airport/airline lounge service categories. Using the 2,242 units of data gathered from airlinequality.com, the study confirms the findings of previous research regarding the importance of service quality with customer behavioral intention, and of cognitive service attributes with atmospheric/affective service attribute. Some implications for lounge service management and future studies are drawn from the outcomes of the exploratory and inferential analyses of the data.
\end{abstract}

Keywords: Lounge Service, Evaluation, Intention, Datamining.

\section{Introduction}

Airline/airport lounges are considered as the "sanctuaries" for premium and high-yield air passengers (Experience the Skies, 2015). The first lounge was opened on 2 December 1939 at New York LaGuardia Airport by American Airlines. It was called "The Flagship Club," and provided bar and food services. In 1970s, British Airways upgraded the lounge service by introducing the "Concord Room" concept, which gives passengers direct access to the plane. In 2004, Lufthansa created the first dedicated lounge with its own full-service bar, bathrooms, cigar lounge, duty free area, luxurious internal transportation, offices, relaxation rooms, restaurant, and security and passport control.

Up to the mid-1990s, passengers of an airline could only have the access to the lounges run by the airline. However, after the Star Alliance (May 1997) and other partnership agreements (e.g., One World, Sky Team) were made, passengers can use the services provided by other airlines of the same network. Some third-party providers (e.g., Plaza Premium, American Express) also participated in the business, which offer more choices for air passengers (Experience the Skies, 2015). Nowadays, the access to lounges is not only limited to high-class passengers, but also open to those who accept the entry fees.

Airline/airport lounge is a determinant for airline selection, and a factor of airline service quality (Han, et al., 2012). However, not much is known about passenger perception and evaluation of airline/airport lounge service. Han, et al.'s (2012), for example, surveyed 307 passengers visiting Korean Airlines' lounge in Incheon Airport about their perception of and satisfaction with lounge services, and also their revisit intention. It was revealed that passenger evaluation of lounge service was structured by the four factors of "atmosphere," "food and beverage," "employee," and "facilities." All of these factors significantly affected the passenger's 
overall satisfaction, and three of them significantly predicted passenger revisit intention (except facilities).

A recent study conducted by Kim, et al. (2016) produces some more insights into the determinants of lounge user satisfaction and intentions. Specifically, when asking 493 users of lounges in the US, Kim et. al. (2016) found that sensory evaluation, cognitive evaluation, affective evaluation, and well-being perception significantly influenced passenger satisfaction. Passenger satisfaction, in its turn, could significantly affect passenger word-of-mouth and revisit intention.

This paper aims to strengthen the thin line of research on airline/airport lounge service by applying the datamining approach. Air passenger evaluations and reviews of lounge service posted on airlinequality.com were collected and analyzed to confirm the findings of previous studies (Han, et al., 2012; Kim, et al., 2016), and to discover the new patterns. The outcomes provide some implications for airline/airport lounge service management and for future research.

\section{Description of the Data}

A total of 2,242 units of data were gathered from airlinequality.com over a period of six years (January 2011 - December 2016). Each unit of data consists of the textual review, the numerical evaluation (5-point scale) of the seven service categories (comfort, cleanliness, bar and beverages, catering, washrooms, Wi-Fi and connection, and staff service), the intention to recommend (yes/no), the corresponding airline/airport, and the access type (business class, first class, frequent flyer).

Table 1 provides a brief description of the data used in this study. Accordingly, almost half of the data involved some of the largest airlines in the world and their home airports. Among them, the reviews on British Airways and London Heathrow Airport accounted for almost 10\% of the data.

Table 1: Description of the data $(n=2,242)$

\begin{tabular}{lrrlrr}
\hline Airlines & Frequency & \% & Airports & Frequency & $\%$ \\
\hline $\begin{array}{l}\text { British Airways } \\
\text { (BA) }\end{array}$ & 221 & 9.9 & London Heathrow (LH) & 213 & 9.5 \\
Emirates (EM) & 131 & 5.8 & $\begin{array}{l}\text { Bangkok Suvarnabhumi } \\
\text { (BS) }\end{array}$ & 82 & 3.7 \\
Qantas Airways & 129 & 5.8 & Hong Kong (HK) & 76 & 3.4 \\
(QnA) & & & & & \\
United Airlines & 122 & 5.4 & Dubai (DB) & 68 & 3.0 \\
(UA) & & & & & \\
Qatar Airways & 87 & 3.9 & Singapore Changi (SC) & 68 & 3.0 \\
(QrA) & & & & & \\
Lufthansa (LT) & 83 & 3.7 & Istanbul Ataturk (IA) & 64 & 2.9 \\
Malaysia Airlines & 69 & 3.1 & Los Angeles LAX & 60 & 2.7 \\
Thai Airways & 67 & 3.0 & New York JFK & 58 & 2.6 \\
Air Canada & 66 & 2.9 & Sydney & 56 & 2.5 \\
Etihad Airways & 66 & 2.9 & KLIA Kuala Lumpur & 54 & 2.4 \\
Others & 1,201 & 53.6 & Others & 1,443 & 64.3 \\
\hline
\end{tabular}

According to airlinequality.com's reviewers, "cleanliness" (mean = 3.69) and "Wi$\mathrm{Fi}$ /connectivity" (mean $=3.59$ ) are the best, while "catering" (mean $=2.87$ ) is the worst among the seven lounge service categories. When examining the six major airlines (Table 2), it is revealed that the services of British Airways and United Airlines are below average; the best 
providers are the three Middle Eastern and Australian airlines, including Emirates, Qantas Airways, and Qatar Airways. All the six major airports provide better-than-average lounge services; the best performers are Hong Kong Airport and Istanbul Ataturk Airport (Table 3). Noticeably, the "staff service" of all the six major airports are indifferently evaluated ( $p>0.05)$.

Table 2: Comparison of lounge service of major airlines

\begin{tabular}{lllllllll}
\hline & $\begin{array}{l}\text { All } \\
(\mathrm{n}=2,242)\end{array}$ & $\begin{array}{l}\text { BA } \\
(\mathrm{n}=221)\end{array}$ & $\begin{array}{l}\text { EM } \\
(\mathrm{n}=131)\end{array}$ & $\begin{array}{l}\text { QnA } \\
(\mathrm{n}=129)\end{array}$ & $\begin{array}{l}\text { UA } \\
(\mathrm{n}=122)\end{array}$ & $\begin{array}{l}\text { QrA } \\
(\mathrm{n}=87)\end{array}$ & $\begin{array}{l}\text { LT } \\
(\mathrm{n}=83)\end{array}$ & $p$ \\
\hline Comfort & 3.39 & 3.25 & 3.65 & 3.73 & 2.70 & 3.98 & 3.46 & 0.000 \\
Cleanliness & 3.69 & 3.51 & 4.15 & 4.21 & 2.91 & 4.47 & 3.92 & 0.000 \\
Bar/beverages & 3.29 & 3.30 & 3.92 & 3.92 & 2.44 & 3.89 & 3.63 & 0.000 \\
Catering & 2.87 & 2.64 & 3.65 & 3.44 & 1.93 & 3.77 & 3.14 & 0.000 \\
Washrooms & 3.22 & 3.10 & 3.40 & 3.87 & 2.48 & 4.01 & 3.57 & 0.000 \\
Wi- & 3.59 & 3.44 & 3.72 & 3.88 & 3.09 & 4.09 & 3.55 & 0.000 \\
Fi/connectivity & & & & & & & & \\
Staff service & 3.37 & 3.22 & 3.78 & 3.98 & 2.52 & 4.25 & 3.58 & 0.000 \\
\hline
\end{tabular}

Table 3: Comparison of lounge service at major airports

\begin{tabular}{lllllllll}
\hline & $\begin{array}{l}\text { All } \\
(\mathrm{n}=2,242)\end{array}$ & $\begin{array}{l}\text { LH } \\
(\mathrm{n}=213)\end{array}$ & $\begin{array}{l}\text { BS } \\
(\mathrm{n}=82)\end{array}$ & $\begin{array}{l}\text { HK } \\
(\mathrm{n}=76)\end{array}$ & $\begin{array}{l}\mathrm{DB} \\
(\mathrm{n}=68)\end{array}$ & $\begin{array}{l}\text { SC } \\
(\mathrm{n}=68)\end{array}$ & $\begin{array}{l}\text { IA } \\
(\mathrm{n}=64)\end{array}$ & $p$ \\
\hline Comfort & 3.39 & 3.69 & 3.50 & 4.13 & 3.35 & 3.49 & 4.09 & 0.000 \\
Cleanliness & 3.69 & 3.78 & 3.93 & 4.45 & 4.01 & 4.00 & 4.06 & 0.003 \\
Bar/beverages & 3.29 & 3.78 & 3.33 & 4.24 & 3.75 & 3.35 & 4.38 & 0.000 \\
Catering & 2.87 & 3.19 & 3.00 & 3.87 & 3.34 & 3.21 & 4.27 & 0.000 \\
Washrooms & 3.22 & 3.61 & 3.26 & 3.93 & 2.84 & 3.53 & 3.89 & 0.000 \\
Wi- & 3.59 & 3.88 & 3.98 & 4.13 & 3.37 & 3.62 & 4.17 & 0.000 \\
Fi/connectivity & & & & & & & & \\
Staff service & 3.37 & 3.53 & 3.79 & 4.03 & 3.54 & 3.65 & 3.62 & 0.117 \\
\hline
\end{tabular}

Among the reviewers, 1,209 had "business class" access, 166 had "first class" access, and 62 got "frequency flyer" access (the remaining 805 did not reveal their access types). Based on this classification, a further analysis was made to compare the evaluations of these three groups $(\mathrm{n}=$ 1,437). According to the outcomes provided in Table 4, the three types of access indifferently evaluated the "bar and beverages," "catering," and "Wi-Fi and connectivity" service categories of the lounges. Otherwise, their perceptions differed in the remaining categories of "comfort," "cleanliness," "washrooms," and "staff service."

Table 4: Comparison of lounge access types

\begin{tabular}{llllll}
\hline & $\begin{array}{l}\text { All } \\
(\mathrm{n}=2,242)\end{array}$ & $\begin{array}{l}\text { Business } \\
\text { class } \\
(\mathrm{n}=1,209)\end{array}$ & $\begin{array}{l}\text { First class } \\
(\mathrm{n}=166)\end{array}$ & $\begin{array}{l}\text { Frequency } \\
\text { flyer } \\
(\mathrm{n}=62)\end{array}$ & $p$ \\
\hline Comfort & 3.39 & 3.33 & 3.58 & 3.68 & 0.013 \\
Cleanliness & 3.69 & 3.61 & 3.89 & 3.89 & 0.010 \\
Bar/beverages & 3.29 & 3.21 & 3.43 & 3.34 & 0.141 \\
Catering & 2.87 & 2.76 & 3.04 & 2.85 & 0.069 \\
Washrooms & 3.22 & 3.09 & 3.52 & 3.61 & 0.000 \\
Wi-Fi & 3.59 & 3.54 & 3.64 & 3.94 & 0.051 \\
/connectivity & & & & & \\
Staff service & 3.37 & 3.30 & 3.54 & 3.68 & 0.017 \\
\hline
\end{tabular}


Table 5: Comparison of perceiver types

\begin{tabular}{lllllll}
\hline & $\begin{array}{l}\text { All } \\
(\mathrm{n}=2,242 ;\end{array}$ & $\begin{array}{l}\text { Cluster 1 } \\
(\mathrm{n}=535 ;\end{array}$ & $\begin{array}{l}\text { Cluster } 2 \\
(\mathrm{n}=598 ;\end{array}$ & $\begin{array}{l}\text { Cluster 3 } \\
(\mathrm{n}=741 ;\end{array}$ & $\begin{array}{l}\text { Cluster } 4 \\
(\mathrm{n}=368 ;\end{array}$ & $p$ \\
& $\mathbf{1 0 0 \% )}$ & $23.86 \%)$ & $26.67 \%)$ & $33.05 \%)$ & $16.41 \%)$ & \\
\hline Comfort & 3.39 & 2.62 & 3.65 & 4.66 & 1.56 & 0.000 \\
Cleanliness & 3.69 & 3.05 & 4.05 & 4.83 & 1.77 & 0.000 \\
Bar/beverages & 3.29 & 2.27 & 3.64 & 4.64 & 1.53 & 0.000 \\
Catering & 2.87 & 1.60 & 3.00 & 4.48 & 1.26 & 0.000 \\
Washrooms & 3.22 & 2.38 & 3.38 & 4.52 & 1.52 & 0.000 \\
Wi- & 3.59 & 3.24 & 3.81 & 4.57 & 1.77 & 0.000 \\
Fi/connectivity & & & & & & \\
Staff service & 3.37 & 2.52 & 3.70 & 4.70 & 1.39 & 0.000 \\
\hline
\end{tabular}

To look deeper into the hidden patterns of the reviewers' perception, cluster analysis (hierarchical cluster analysis using Ward's method and $k$-mean cluster analysis) was conducted. Four clusters were determined; the perceptions of these clusters were found to be heterogeneous (Table 5).

\section{Research Issues, Data Analysis and Findings}

\section{1 Perception of Service Categories and Consequent Behaviors}

Han, et al.'s (2012) study found that "food and beverage service" $(\beta=0.338, p<0.01)$, "atmosphere" $(\beta=0.212, p<0.01)$, and "employee service" $(\beta=0.161, p<0.01)$ are the three significant predictors of lounge customers' revisit intention. To extend Han, et al.'s (2012) effort, this study uses the airlinequality.com data to verify the correlation between lounge service categories and lounge customer's intention to recommend.

H1. Lounge customer evaluation of lounge service categories significantly affects their intention to recommend the lounge.

To verify the first hypothesis, four separate regression analyses were conducted in SPSS (Table $6 \mathrm{a}, 6 \mathrm{~b}$ ). As a result, the overall model (lounge service evaluation $\rightarrow$ lounge recommendation intention) was supported (all the adjusted $R^{2}>0.50, p<0.001$ ). However, in the cases of British Airways and Heathrow Airport, only two out of seven service categories (bar and beverages, and catering) had some significant effects on customer intention. In the remaining cases, six out of seven service categories (except cleanliness) significantly contributed to the prediction of customer intention. Among these categories, comfort was the most important predictor, following by catering, staff service, bar and beverages, Wi-Fi and connection, and washrooms.

Table 6a: Predicting customer intention for airways

\begin{tabular}{|c|c|c|c|c|}
\hline & \multicolumn{2}{|c|}{ 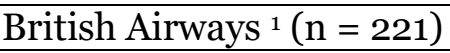 } & \multicolumn{2}{|c|}{ Other airlines ${ }^{2}(n=2,021)$} \\
\hline & $\beta$ & $p$ & $\beta$ & $p$ \\
\hline Comfort $\rightarrow$ Intention & 0.061 & 0.469 & 0.222 & 0.000 \\
\hline Cleanliness $\rightarrow$ Intention & 0.030 & 0.706 & 0.028 & 0.307 \\
\hline $\begin{array}{r}\text { Bar/beverages } \rightarrow \\
\text { Intention }\end{array}$ & 0.211 & 0.015 & 0.106 & 0.000 \\
\hline Catering $\rightarrow$ Intention & 0.286 & 0.001 & 0.193 & 0.000 \\
\hline Washrooms $\rightarrow$ Intention & 0.056 & 0.433 & 0.075 & 0.002 \\
\hline $\begin{array}{r}\mathrm{Wi}-\mathrm{Fi} / \text { connection } \rightarrow \\
\text { Intention }\end{array}$ & 0.076 & 0.249 & 0.079 & 0.000 \\
\hline Staff service $\rightarrow$ Intention & 0.137 & 0.092 & 0.159 & 0.000 \\
\hline
\end{tabular}


Note. ${ }^{1}$ Adjusted $R^{2}=0.550, p=0.000 ;{ }^{2}$ Adjusted $R^{2}=0.551, p=0.000$

Table 6b.Predicting customer intention for airports

\begin{tabular}{rcccc}
\hline & \multicolumn{2}{c}{${\text { Heathrow } \text { Airport }^{1}(\mathrm{n}=213)}^{2}$} & Other airports $^{2}(\mathrm{n}=2,029)$ \\
\hline Comfort $\rightarrow$ Intention & $\beta$ & $p$ & $\beta$ & $p$ \\
Cleanliness $\rightarrow$ Intention & 0.039 & 0.701 & .217 & .000 \\
Bar/beverages $\rightarrow$ & 0.225 & 0.586 & .025 & .348 \\
Intention & & 0.016 & .111 & .000 \\
Catering $\rightarrow$ Intention & 0.278 & & & .000 \\
Washrooms $\rightarrow$ Intention & 0.053 & 0.572 & .074 & .001 \\
Wi-Fi/connection $\rightarrow$ & 0.085 & 0.183 & .080 & .000 \\
Intention & & & & .000 \\
Staff service $\rightarrow$ Intention & 0.126 & 0.138 & .160 & .000 \\
\hline
\end{tabular}

Note. ${ }^{1}$ Adjusted $R^{2}=0.581, p=0.000 ;{ }^{2}$ Adjusted $R^{2}=0.548, p=0.000$

In addition, to reveal the major components of each lounge service category, the word-count tactic was implemented in the Microsoft Word environment. The results of counting the first $10 \%$ of the comments (word numbers $=196,477$ ) were presented in Table 7 . Accordingly, the most frequently mentioned attribute of lounge comfort is its crowdedness. In the bar and beverages category, the most popular drinks are coffee, beers, wines, and soft drinks. Those of the catering category include snacks, sandwiches, soup, and bread; the most important meal served in the lounges is breakfast. In the category of Wi-Fi and connection, newspapers and magazines are also two important components, in addition to TVs, power sockets, PCs, and printers. Staff service, especially reception service, is frequently mentioned together with staff friendliness and helpfulness. Other service components include, for example, seating, view, access, chairs, tables, and design.

Table 7: Major components of each service category

\begin{tabular}{|c|c|c|c|c|c|c|c|}
\hline Comfort & Freq. & Cleanliness & Freq. & Bar/beverages & Freq. & Catering & Freq. \\
\hline Crowded & 347 & cleaning & 38 & coffee & 286 & snacks & 253 \\
\hline Excellent & 318 & cleaned & 34 & alcohol & 202 & breakfast & 180 \\
\hline Limited & 311 & cleared & 29 & beers & 176 & sandwich & 176 \\
\hline$t_{t}^{\text {disappoin }}$ & 224 & clearing & 28 & wines & 103 & $\begin{array}{l}\text { es } \\
\text { cheese }\end{array}$ & 152 \\
\hline Plenty & 222 & spotless & 23 & soft drinks & 102 & buffet & 149 \\
\hline Quiet & 212 & & & champagne & 101 & soup & 136 \\
\hline Pleasant & 195 & & & juice & 79 & empty & 97 \\
\hline Busy & 180 & & & spirits & 75 & bread & 82 \\
\hline Spacious & 180 & & & & & noodle & 76 \\
\hline Basic & 133 & & & & & $\begin{array}{c}\text { self- } \\
\text { service }\end{array}$ & 72 \\
\hline
\end{tabular}

\begin{tabular}{llllllll}
\hline Washrooms & Freq. & $\begin{array}{l}\text { Wi- } \\
\text { Fi/connection }\end{array}$ & Freq. & Staff service & Freq. & Others & Freq. \\
\hline Towel & 59 & newspaper & 120 & friendly & 272 & seating & 385 \\
& & computer & 115 & helpful & 145 & view & 294 \\
& & TV & 100 & reception & 129 & access & 247 \\
& & working & 79 & attentive & 85 & chairs & 238 \\
\hline
\end{tabular}




\begin{tabular}{llllll} 
magazines & 72 & English & 61 & tables & 174 \\
power & 71 & rude & 59 & design & 106 \\
PC & 47 & efficient & 55 & located & 101 \\
print & 47 & polite & 53 & sleep & 88 \\
& & & & décor & 82 \\
& & & & window & 80 \\
\hline
\end{tabular}

\section{2 Functional and Atmospheric/Affective Service Categories}

Among the seven service categories measured by airlinequality.com, "comfort" can be considered as an atmospheric/affective attribute (the attributes which a customer can feel and sense), while the remaining are the cognitive ones (the attributes which a customer can see and touch) (Echtner \& Ritchie, 2003). Baloglu and McCleary (1999), in their seminal study, found that the cognitive perception can participate in the formation of the affective perception. Following Baloglu and McCleary (1999), this study aims to verify the correlation between the cognitive categories and the atmospheric/affective category of airline/airport lounges.

H2. Lounge customer evaluation of cognitive lounge service categories significantly affects their evaluation of atmospheric/affective lounge service category (comfort).

Regression analyses were also implemented to verify the second hypothesis. The outcomes (Table 8a, 8b) support the overall model (cognitive service evaluation $\rightarrow$ affective service evaluation) (all the adjusted $R^{2} \approx 0.70, p<0.001$ ). In the cases of British Airways and Heathrow Airport, half of the cognitive service categories (cleanliness, bar and beverages, and washrooms) had some significant influences on customers' affective evaluation. In the remaining cases, all the six cognitive service categories could generate some desired effects. The importance of each cognitive service categories descend from cleanliness, washrooms, bar and beverages, catering, Wi-Fi and connection, to staff service.

\section{Discussion and Concluding Remark}

The majority of airline/airport lounge users are high-class customers (first class, business class). Since they pay more, they have the right to expect more. However, the exploratory analysis of customer evaluations shows that lounge services are almost perceived at the average level (3 points out of 5 points). In addition, approximately 40\% of the reviewers (clusters 1 and 4) were not very happy with the current services. Some airlines/airports do better than others; yet, there are rooms for all of them to improve the quality of their lounge services, especially the catering service.

Table 8a: Predicting atmospheric/affective perception for airways

\begin{tabular}{rcccc}
\hline & \multicolumn{2}{c}{${\text { British } \text { Airways }^{1}(\mathrm{n}=221)}^{2}$} & \multicolumn{2}{c}{ Other airlines ${ }^{2}(\mathrm{n}=2,021)$} \\
\hline Cleanliness $\rightarrow$ Comfort & $\beta$ & $p$ & $\beta$ & $p$ \\
Bar/beverages $\rightarrow$ & 0.327 & 0.000 & 0.322 & 0.000 \\
Comfort & & 0.000 & 0.159 & 0.000 \\
Catering $\rightarrow$ Comfort & 0.124 & 0.066 & 0.127 & 0.000 \\
Washrooms $\rightarrow$ Comfort & 0.199 & 0.001 & 0.161 & 0.000 \\
Wi-Fi/connection $\rightarrow$ & 0.033 & 0.537 & 0.112 & 0.000 \\
Comfort & & & & \\
Staff service $\rightarrow$ Comfort & 0.001 & 0.990 & 0.102 & 0.000 \\
\hline
\end{tabular}

Note. $\quad{ }^{1}$ Adjusted $R^{2}=0.702, p=0.000 ;{ }^{2}$ Adjusted $R^{2}=0.710, p=0.000$ 
Table 8a.Predicting atmospheric/affective perception for airports

\begin{tabular}{rcccc}
\hline & \multicolumn{2}{c}{ Heathrow Airport $^{1}(\mathrm{n}=213)$} & \multicolumn{2}{c}{ Other airlines $^{2}(\mathrm{n}=2,029)$} \\
\hline Cleanliness $\rightarrow$ Comfort & $\beta$ & $p$ & $\beta$ & $p$ \\
Bar/beverages $\rightarrow$ & 0.409 & 0.000 & 0.321 & 0.000 \\
Comfort & & 0.001 & 0.162 & 0.000 \\
Catering $\rightarrow$ Comfort & 0.094 & 0.111 & 0.130 & 0.000 \\
Washrooms $\rightarrow$ Comfort & 0.141 & 0.028 & 0.163 & 0.000 \\
Wi-Fi/connection $\rightarrow$ & 0.075 & 0.090 & 0.108 & 0.000 \\
Comfort & & & & \\
Staff service $\rightarrow$ Comfort & 0.059 & 0.318 & 0.096 & 0.000 \\
\hline
\end{tabular}

Note. ${ }^{1}$ Adjusted $R^{2}=0.799, p=0.000 ;{ }^{2}$ Adjusted $R^{2}=0.698, p=0.000$

Catering service and bar/beverages service are the most important influencers of customers' intention to recommend British Airways and Heathrow Airport. This outcome is consistent with the finding of Han, et al. (2012). However, the analysis of the larger subset of the data (the remaining airlines and airports) reveals that all service categories, with an exception of cleanliness, are important to customer intention. Interestingly, cleanliness is the most powerful predictor of customer evaluation of lounge comfort, which is the strongest predictor of customer intention. This outcome indicates that although the importance of each service category may vary, none of them can be ignored in the process of lounge service delivery.

The pair of British Airways (airline) and Heathrow Airport (home airport) illustrates an interesting consistency of customer evaluation of lounge services. In both cases, catering and bar/beverages services were the only significant predictors of customer intention. However, the exploratory analysis of the data points out that the best airlines are Emirates, Qantas Airways and Qatar Airways, while the best airports are Hong Kong and Istanbul Ataturk. Thus, the consistency of lounge service delivery of an airline at different airports should be further examined by future studies.

In addition, the word-count analysis, although simple, has added that the classification of lounge services into seven major categories of airlinequality.com is reliable. However, other components should also be taken into account including, for example, lounge location and access, and facilities and design. This observation is consistent with the factor analysis of lounge services undertaken earlier by Han, et al. (2012). Future studies may refer to the list of attributes presented in Table 7 for a broader reference. Moreover, with the participation of third-party providers and economy-class passengers as pay-per-use customers, future studies should also examine several consequent issues, for example, customer expectation and satisfaction, service quality and consistency, and the contribution of lounge service to the total performance of an airport/airline.

In conclusion, this study, with the help of the datamining approach, has confirmed the existing theory regarding the role of customers' evaluation of lounge service and their behavioral intentions. Some implications for airline/airport lounge service management have been deduced from this finding. However, researchers should do more to build up a more thorough understanding of the providers and the customers of airline/airport lounges. 


\section{References}

i. Baloglu, S. \& McCleary, K., 1999. A model of destination image formation. Annals of Tourism Research, 26(4), pp. 868-897.

ii. Echtner, C. \& Ritchie, J., 2003. The meaning and measurement of destination image. The Journal of Tourism Studies, 14(1), pp. 37-48.

iii. $\quad$ Experience the Skies, 2015. Use of airline lounges as a marketing tool - History and innovation. [Online]

Available at: $\quad$ http://www.experiencetheskies.com/use-of-airline-lounges-as-a-marketingtoolhistory-and-innovation/

[Accessed 29 March 2017].

iv. Han, S., Ham, S., Yang, I. \& Baek, S., 2012. Passengers' perceptions of airline lounges Importance of attributes that determine usage and service quality measurement. Tourism Management, 35(3), pp. 1103-1111.

v. Kim, H., 2016. Understanding airline travelers' perceptions of well-being: The role of cognition, emotion, and sensory experiences in airline lounges.. Journal of Travel \& Tourism Marketing, 33(9), pp. 1213-1234. 